\title{
Incorporação de clorexidina à superfície da liga Ti7,5Mo após modificação de superfície com crescimento de nanotubos de $\mathrm{TiO}_{2}$ associado a eletrofiação
}

\author{
Incorporation of chlorhexidine to Ti7.5Mo alloy surface after surface modification \\ with growth of nanotubes of $\mathrm{TiO}_{2}$ associated to electrospinning \\ Incorporación de clorhexidina en la superfície de la aleación Ti7,5Mo \\ después de la modificación de la superfície com crecimiento de nanotubos de \\ $\mathrm{TiO}_{2}$ asociado a electrospinning \\ João Pedro Aquiles CAROBOLANTE ${ }^{1}$
Liliane Lelis de OLIVEIRA $^{1}$ \\ Rosemeire dos Santos ALMEIDA ${ }^{2}$ \\ Marcos Akira D'ÁVILA \\ Ana Paula Rosifini ALVES CLARO ${ }^{1}$ \\ ${ }^{I}$ Faculdade de Engenharia de Guaratinguetá, UNESP-Univ Estadual Paulista, Guaratinguetá - SP, Brasil \\ ${ }^{2}$ Faculdade de Tecnologia Mauá, FATEC-Mauá, Mauá - SP, Brasil; \\ Faculdade de Tecnologia de Campinas, FATEC-Campinas, Campinas-SP, Brasil \\ ${ }^{3}$ Faculdade de Engenharia Mecânica de Campinas, UNICAMP-Univ Estadual Campinas, Campinas-SP, Brasil
}

\begin{abstract}
Resumo
Ligas de titânio são amplamente utilizadas na reparação de tecido ósseo devido suas excelentes propriedades de volume. Neste estudo foram analisado o potencial bactericida de tratamentos de superfície na liga Ti7,5Mo. As amostras foram anodizadas em $\mathrm{NH}_{4} \mathrm{~F} / \mathrm{H}_{2} \mathrm{O} /$ glicerol para crescimento de nanotubos de $\mathrm{TiO}_{2}$, posteriormente foram cobertas com uma manta de PCL eletrofiado e realizado a incorporação de clorexidina por dois métodos, imersão e gotejamento. A superfície foi analisada por microscopia eletrônica de varredura e medidas de ângulo de contato. O efeito bactericida foi analisado por meio da cultura de $C$. albicans e S. aureus. A incorporação por imersão apresentou resultados mais satisfatórios.

Descritores: Materiais Biocompativeis; Titânio; Ligas; Nanotubos; Propriedades de Superfície.
\end{abstract}

\begin{abstract}
Titanium alloys are widely used in the repair of bone tissue due to their excellent properties. In this study the bactericidal potential of surface treatments in the Ti7.5Mo alloy was analyzed. The samples were anodized in $\mathrm{NH}_{4} \mathrm{~F} / \mathrm{H}_{2} \mathrm{O} / \mathrm{glycerol}$ for the growth of $\mathrm{TiO}_{2}$ nanotubes, later covered with electrolyzed PCL and made the incorporation of chlorhexidine by two methods, immersion and dripping. The surface was analyzed by scanning electron microscopy and contact angle measurements. The bactericidal effect was analyzed by culture of $C$. albicans and $S$. aureus. The incorporation by immersion presented more satisfactory results.

Descriptors: Biocompatible Biomaterials; Titanium; Alloys; Nanotubes; Surface Properties.
\end{abstract}

\section{Resumen}

Las aleaciones de titanio son ampliamente utilizadas en la reparación del tejido óseo debido a sus excelentes propiedades. En este estudio se analizó el potencial bactericida de los tratamientos superficiales en la aleación Ti7.5Mo. Las muestras se anodizaron en $\mathrm{NH}_{4} \mathrm{~F} / \mathrm{H}_{2} \mathrm{O}$ /glicerol para el crecimiento de nanotubos de $\mathrm{TiO}_{2}$, posteriormente se cubrieron con PCL electrolizada e hicieron la incorporación de clorhexidina por dos métodos, inmersión y goteo. La superficie se analizó mediante microscopía electrónica de barrido y mediciones de ángulos de contacto. El efecto bactericida se analizó mediante cultivo de $C$. albicans y $S$. aureus. La incorporación por inmersión presentó resultados más satisfactorios.

Descriptores: Materiales Biocompatibles; Titanio; Aleaciones; Nanotubos; Propiedades de Superficie.

\section{INTRODUÇÃO}

O titânio e suas ligas são utilizados na reparação ou substituição do tecido ósseo devido suas excelentes propriedades de volume, como alta resistência à tração e compressão, baixa densidade e módulo de elasticidade inferior quando comparado a outros materiais metálicos empregados, como ligas cobalto-cromo e aços inoxidáveis ${ }^{1}$. Além disso, apresentam excelente biocompatibilidade e resistência à corrosão, devido à formação de uma camada de óxido de titânio $\left(\mathrm{TiO}_{2}\right)$ que lhe confere a passividade, dificultando a liberação de íons que ao entrar em contato com o organismo podem causar metalose e necrose levando a perda do implante ${ }^{2}$. Porém estas propriedades de volume já estão bem estabelecidas e na atualidade se busca modificar a superfície procurando melhorar a interação na interface implante/osso, facilitando o crescimento do tecido (osseointegração) e diminuindo reações adversas.
Estudos sobre a topografia de superfície mostram que nanotubos de $\mathrm{TiO}_{2}$ podem contribuir para uma melhor adesão celular. Na década de 1990 estudos pioneiros foram realizados para avaliar a formação de nanotubos de $\mathrm{TiO}_{2}$ empregando oxidação anódica. Desde então, o estudo dos parâmetros do processo de anodização para emprego de nanotubos em aplicações biomédicas tem sido avaliado por diversos autores ${ }^{3-6}$. É interessante observar que o volume aberto criado pela formação de nanotubos de $\mathrm{TiO}_{2}$ pode ser empregado como um reservatório para medicamentos com sua posterior liberação ${ }^{6}$.

O emprego desses materiais como sistemas de liberação de estreptomicina/penicilina empregando adsorção física e a incorporação por imersão em SBF (Simulated Body Fluid) foi avaliado por Aniwene et al. ${ }^{8}$. No entanto, apesar da sua viabilidade, o uso dessas técnicas pode ser 
limitado devido à tensão superficial que pode inibir a liberação de drogas ou ainda pela ausência do controle da liberação.

A deposição de filmes poliméricos por eletrofiação consiste em outra técnica que tem sido empregada na funcionalização de nanotubos, devido à sua capacidade de produzir fibras na faixa submicrométrica e nanométrica ${ }^{9,10}$. O processo consiste na aplicação de um forte campo elétrico em uma solução polimérica ou um polímero fundido o qual pode ser aplicado em uma variedade de polímeros, algo difícil de atingir utilizando outras técnicas de fiação ${ }^{11-13}$. O sistema de eletrofiação consiste basicamente em uma bomba de infusão, uma fonte de alimentação de alta voltagem, uma seringa com a solução polimérica ou o polímero fundido, e um sistema coletor ${ }^{12}$. O coletor pode apresentar diversas formas como, por exemplo, uma chapa ou um cilindro, que são confeccionados de material condutor para que as cargas possam ser dissipadas, facilitando a deposição contínua das fibras. O tipo de coletor influencia a disposição das fibras na manta. Coletores mais simples como uma chapa metálica produzem nanofibras com orientações aleatórias na manta ${ }^{14}$.

Nos sistemas de liberação de drogas a partir de nanofibras dois processos de fabricação podem ser empregados: co-eletrofiação ou imobilização física e química. De acordo com o processo de fabricação escolhido dentro ou sobre a fibra é esperado um tipo de liberação. A incorporação de medicamentos dentro das nanofibras apresenta elevada eficiência de liberação associada com as nanopartículas ou microesferas que são liberadas de dentro das microfibras. Diversas drogas podem ser co-eletrofiadas incluindo moléculas, antibiótico e proteínas, sendo que a sua solubilidade irá definir o método de liberação ${ }^{15}$. Drogas hidrofóbicas, como a doxorubicina e paclitaxel são eletrofiadas com solventes orgânicos enquanto drogas hidrofílicas, tais como peptídeos e proteínas são dissolvidas em fases aquosas com poli(álcool vinil) (PVA) ou polietilenoglicol (PEO). Entretanto, a exposição de drogas a solventes orgânicos e alta voltagem, pode ser prejudicial para medicamentos especialmente moléculas bioativas. Além disso, métodos de liberação com a simples mistura droga-carregamento exibem tempos de liberação curtos resumidos em poucos dias. Isto porque a liberação de drogas no estágio inicial é resultado de uma difusão simples enquanto os outros estágios consistem na degradação do polímero. No caso das nanofibras, os medicamentos são liberados em altas doses devido a elevada relação superfície/volume característica desses materiais. Por outro lado, a imobilização física e química pode evitar a desnaturação causada pela alta voltagem ou solventes orgânicos, com a vantagem da elevada relação superfície/volume. É possível controlar a quantidade de medicamentos imobilizados pelo controle da taxa de alimentação do medicamento.

A partir do exposto, o objetivo dessa pesquisa foi a incorporação de clorexidina à superfície da liga Ti7,5Mo após crescimento de nanotubose posterior recobrimento com poli-caprolactona eletrofiada.

\section{MATERIAL E MÉTODO}

\section{○ Obtenção das Amostras}

A liga Ti-7,5Mo foi obtida a partir de titânio comercialmente puro (Sandinox) e molibdênio 99,99\% na forma de chapas. Após pesagem e decapagem química, os metais foram colocados no interior do forno a arco voltaico com atmosfera inerte (argônio) em um cadinho de cobre refrigerado a água. Após o fechamento da câmara foi realizada a purga para retirada do oxigênio e feita injeção do gás argônio para a fusão. Durante a fusão, os lingotes foram refundidos pelo menos 10 vezes para garantir a homogeneidade da liga. Os lingotes foram submetidos a tratamento térmico de homogeneização a $1000{ }^{\circ} \mathrm{C}$, seguido de solubilização a $950{ }^{\circ} \mathrm{C}$ por duas horas e forjamento rotativo a frio. As barras forjadas (diâmetro de $8 \mathrm{~mm}$ ) foram seccionadas de tal forma que discos com $3 \mathrm{~mm}$ de espessura fossem obtidos.

\section{○ Oxidação Anódica}

Antes da modificação da superfície por oxidação anódica, as amostras foram preparadas passando respectivamente pelas seguintes etapas: lixamento úmido, com lixas de granas 400, 600, 1000, 1200 e 1500; polimento com solução formada por água e sílica coloidal (1:1) mais ácido oxálico (5\%). Após essa etapa as amostras foram limpas em banho ultrassônico em água deionizada e sabão neutro, em seguida, imersas em água deionizada e finalizando o processo de limpeza, imersas em Etanol 98\%, sendo a duração de cada etapa equivalente há 20 minutos.

O eletrólito e parâmetros empregados para a oxidação anódica foram baseados em nossos estudos anteriores para a liga $\mathrm{Ti7}, 5 \mathrm{Mo}^{17}$. O eletrólito empregado era formado por glicerol e água (9:1, em volume) contendo $0,25 \% \mathrm{NH}_{4} \mathrm{~F}$. O processo de anodização foi realizado a $10 \mathrm{~V}$ por 24 horas, a temperatura ambiente. A calcinação foi realizada a $450{ }^{\circ} \mathrm{C}$, durante 1 hora, com taxa de aquecimento de $5{ }^{\circ} \mathrm{C} / \mathrm{min}$, seguido de resfriamento lento dentro do forno.

Após a oxidação anódica, as amostras foram divididas em dois grupos. $\mathrm{O}$ primeiro formado por amostras com a superfície recoberta com nanotubos de $\mathrm{TiO}_{2}$ (TNT), e o segundo, onde após a anodização, foi realizada a eletrofiação de PCL.

\section{○ Eletrofiação}

Uma solução de PCL (MM $70.000 \mathrm{~g} / \mathrm{mol}$ $90.000 \mathrm{~g} / \mathrm{mol}$ ) (Sigma Aldrich) /clorofórmio (Merck, 99,0\%)/acetona (Synth, 99,5\%) (13,6:43,2:43,2, em massa) foi utilizado durante a eletrofiação. Os parâmetros aplicados foram: tensão contínua de $12,0 \mathrm{KV}$, tensão alternada de 7,2 KV sob frequência de $205 \mathrm{~Hz}$ por meio de uma fonte de alimentação CA/CC simultânea (Testtech). Foi empregada uma vazão de $8 \mathrm{~mL} / \mathrm{h}$, utilizando uma bomba de infusão (KD Scientific, mod. KD-100), com saída da solução em uma agulha de aço inoxidável de $1,0 \mathrm{~mm}$ de diâmetro. As amostras foram fixadas a um anteparo coletor de alumínio distante $120 \mathrm{~mm}$ da agulha. O PCL foi eletrofiado sobre os discos de Ti7,5Mo durante 120s.

\section{○ Incorporação de Medicamento}

A clorexidina foi adquirida em farmácia de homeopatia sendo usada a concentração de $0,2 \%$. Para a incorporação de clorexidina foram empregadas duas técnicas: gotejamento e imersão, caracterizando os subgrupos da divisão anterior. Para o gotejamento, com o auxílio de uma pipeta foram depositados $8 \mu \mathrm{L}$ sobre cada amostra, sendo em seguida colocada em dessecador a vácuo por 2 hora. Esse procedimento foi repetido duas vezes. Após a última secagem as amostras foram enxaguadas com $5 \mu \mathrm{L}$ de PBS e armazenadas no dessecador sob vácuo.

Para as amostras pertencentes a esse grupo, antes da incorporação da clorexidina e após a eletrofiação, as amostras foram submetidas a tratamento a plasma, em reator de aço inoxidável, conforme estudo realizado anteriormente $^{17}$. Os parâmetros utilizados para esse tratamento foram pressão de $0,2 \mathrm{mBar}$ de oxigênio, com 20 $\mathrm{kV}$ por 5 minutos empregando uma fonte de radio frequência $(13,56 \mathrm{MHz})$. 
O procedimento para incorporação por imersão foi realizado submergindo as amostras na solução de clorexidina durante $30 \mathrm{~min}$. Seguido de secagem em dessecador sob vácuo.

Após a incorporação da clorexidina as amostras foram esterilizadas com dose de $25 \mathrm{kGy}$, na fonte de Cobalto- 60 , irradiação gamma, com taxa de dose de $0,883 \mathrm{kGy} / \mathrm{h}$ com o tempo de 28,3h. A esterilização foi feita no Instituto de Pesquisas Energéticas e Nucleares - Centro de Tecnologia das Radiações IPEN/CTR.

\section{- Caracterização das Amostras}

\section{- Microscopia Eletrônica de Varredura}

A avaliação da superfície após os tratamentos foi realizada utilizando microscópios eletrônicos de varredura (Zeiss MEV EVO LS 15 e Philips XL-30 FEG) com tensão de aceleração de 1,12 e $20 \mathrm{kV}$. As amostras eletrofiadas com PCL e/ou após a cultura de bactérias foram previamente metalizadas com ouro (Baltec, model SCD050).

- Ângulo de Contato

A molhabilidade foi analisada pela medida do ângulo de contato, utilizando o método da gota séssil em um goniômetro (modelo DSA 100, Krüss). O procedimento foi realizado sob temperatura ambiente, com uma gota de água deionizada de $5 \mu \mathrm{L}$. As imagens foram capturadas após a estabilização da gota.

- Análise da Adesão Bacteriana

Dois tipos de cepas foram usadas nesse estudo Candida albicans (ATCC 18804) eStaphylococcus aureus (ATCC 6538).

Foram preparadas suspensões padrão de cada cepa com densidade óptica equivalente a $10^{6}$ células $/ \mathrm{mL}$. As cepas foram cultivadas a $37^{\circ} \mathrm{C}$ por 24 horas em meio Sabouraud agar (Difco, Detroit, USA) para C. albicans ou caldo Brain Heart infusion (BHI) agar (Difco, Detroit, USA) for $S$. aureus.

Após incubação, as células foram resuspensas em solução tampão estéril PBS $(0,1 \mathrm{M}, \mathrm{pH} 7,2)$, o número de células em suspensão foi contado em um espectrofotômetro (B582, Micronal, São Paulo, Brazil). Os parâmetros de densidade óptica e comprimento de onda utilizados foram 0,284 e 530 para C. albicans, e 0,374 e $490 \mathrm{~nm}$ para $S$. aureus.

A formação de biofilme foi desenvolvido como proposto por Pereira et al. ${ }^{18}$ (2011), com algumas modificações. Os biofilmes forram cultivadas em discos de $8 \mathrm{~mm}$ de diâmetro e $3 \mathrm{~mm}$ de espessura. As amostras foram em uma placa de 24 poços (Costar Corning, New York, USA), contendo $2 \mathrm{~mL}$ de caldo Brain Heart infusion (BHI) agar (Difco, Detroit, USA) suplementando com 5\% de sacarose e inoculados com $0,1 \mathrm{~mL}$ de suspensão microbial. A incubação ocorreu a 37 ${ }^{\circ} \mathrm{C}$ durante $48 \mathrm{~h}$. O meio não foi alterado durante o período.

Após as $48 \mathrm{~h}$ de incubação, as amostras contendo os biofilmes foram assepticamente lavados duas vezes com 2 $\mathrm{mL}$ de PBS para remover o material fracamente ligado.

As amostras foram colocadas em tubos contendo $10 \mathrm{~mL}$ de PBS elevados ao ultrassom (50 W, Sonics Vibra Cell, Connecticut, EUA) durante $30 \mathrm{~s}$ para dispersar os biofilmes. As suspensões de biofilmes foram diluídas, entre $10^{-1}$ e $10^{-8}$ da concentração original.

Alíquotas de $100 \mu \mathrm{L}$ de cada diluição forma cultivadas em Agar (em duplicata): Sabouraud dextrose agar com 50 mg/L de cloranfenicol(União Química, São Paulo, Brazil) para Candida albicans, e em Manitol Agar (Difco, Detroit, USA) para Staphylococcus aureus.

Após 48 horas de incubação, o número de unidades formadoras de colônias por mililitro (CFU/mL) foi determinado e analisado pela análise de variância (ANOVA) e teste de Tukey. Um valor de $\mathrm{P}<0,05$ foi considerado para indicar uma diferença estatisticamente significativa.

\section{RESULTADOS E DISCUSSÃO}

Neste estudo foram analisadas diferentes modificações de superfície a fim de observar o potencial bactericida de cada tratamento. A figura $1 \mathrm{a}$ e $1 \mathrm{~b}$ apresentam a superfície da liga Ti7,5Mo após oxidação anódica. Os nanotubos de $\mathrm{TiO}_{2}$ (TNT) cresceram de forma homogênea sobre a superfície, com diâmetro interno médio de $26,8 \mathrm{~nm}$. A anodização foi empregada, pois o crescimento de nanotubos é uma técnica que permite uma melhor osseointegração devido ao aumento da rugosidade da superfíce $^{19}$.

Posteriormente, o PCL foi eletrofiado sobre a superfície anodizada (Figuras 1c) com a intenção de atuar como agente regulador da liberação do medicamento incorporado e como agente facilitador da osseointegração devido sua arquitetura, como pode ser observado na Figura $1 \mathrm{~d}^{16}$.
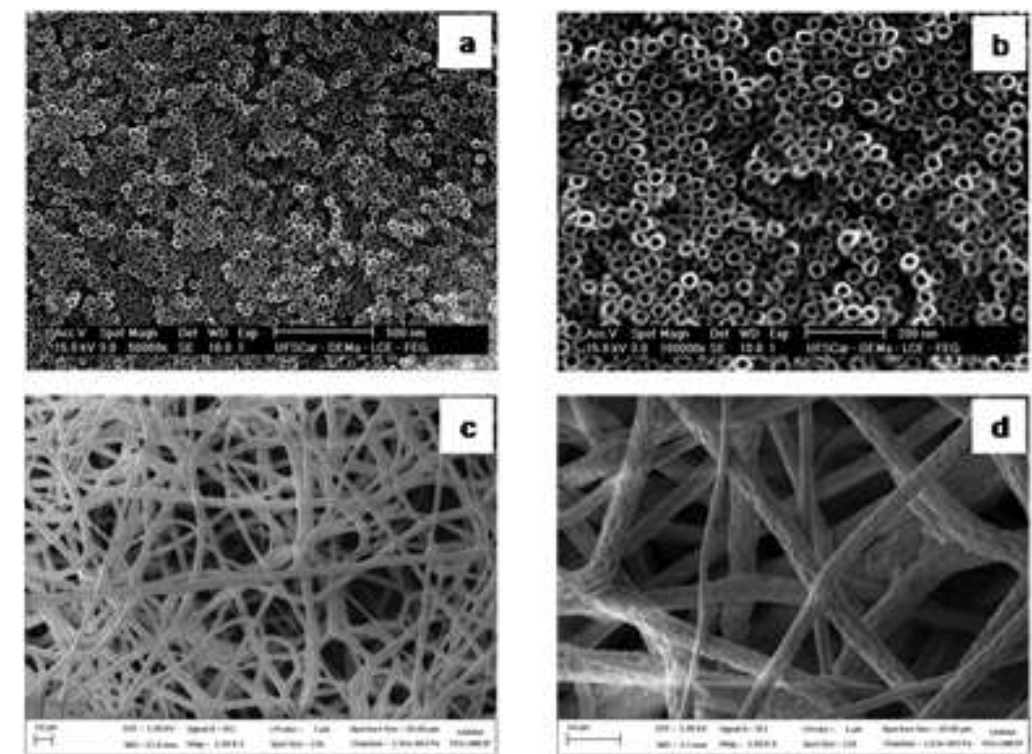

Figura 1: Microscopias após o crescimento de $(\mathrm{a}, \mathrm{b})$ nanotubos de $\mathrm{TiO}$ na superfície da liga Ti7,5Mo e (c, d) do PCL após eletrofiação.

A Tabela 1 apresenta os ângulos de contato das superfícies estudadas todas as superfícies apresentaram caráter hidrofílico ou superhidrofílico. No caso da incorporação da solução de clorexidina por gotejamento foi necessário a realização de um tratamento a plasma, pois o PCL é hidrofóbico, assim não seria possível o espalhamento da gota, dificultando a incorporação do medicamento.

Tabela 1. Medidas de ângulo de contato e aspecto da gota

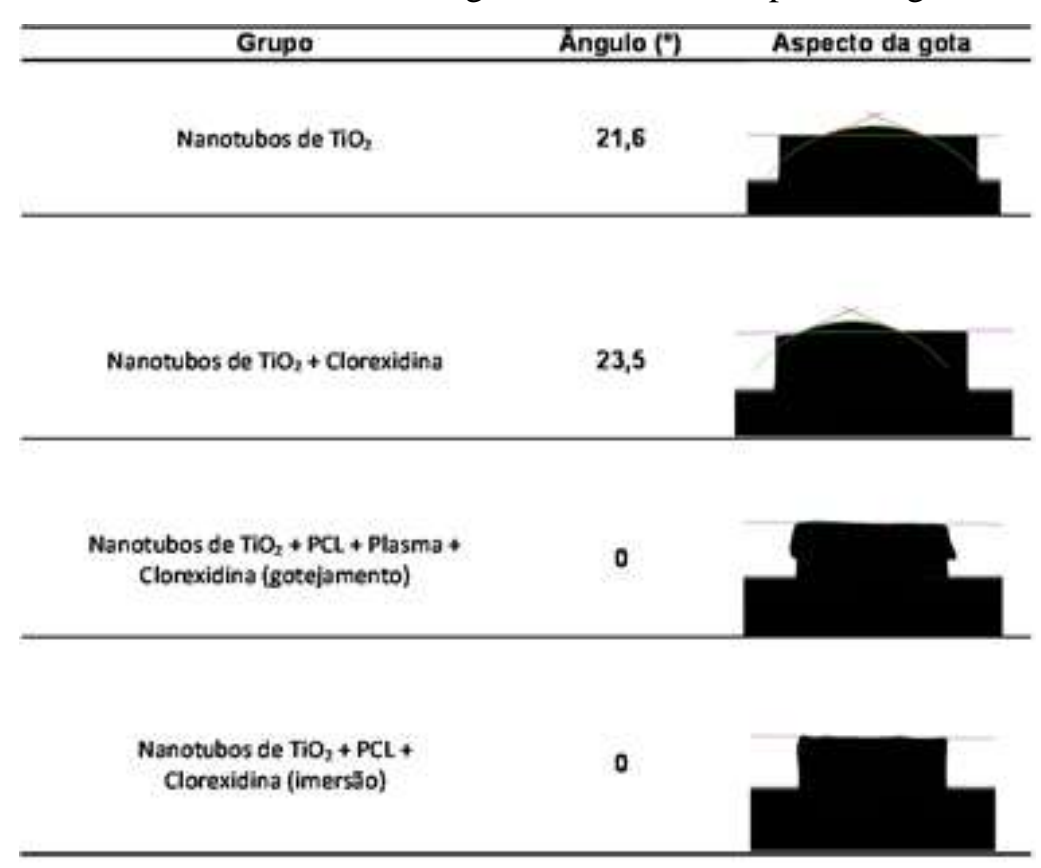


Para análise do potencial bactericida dos tratamentos foram utilizados os microorganismos $C$. albicans, por pertencer a um gênero comumente encontrado na cavidade oral, e S. aureus, pois é um dos principais causadores de infecções cirúrgicas ${ }^{20}$.

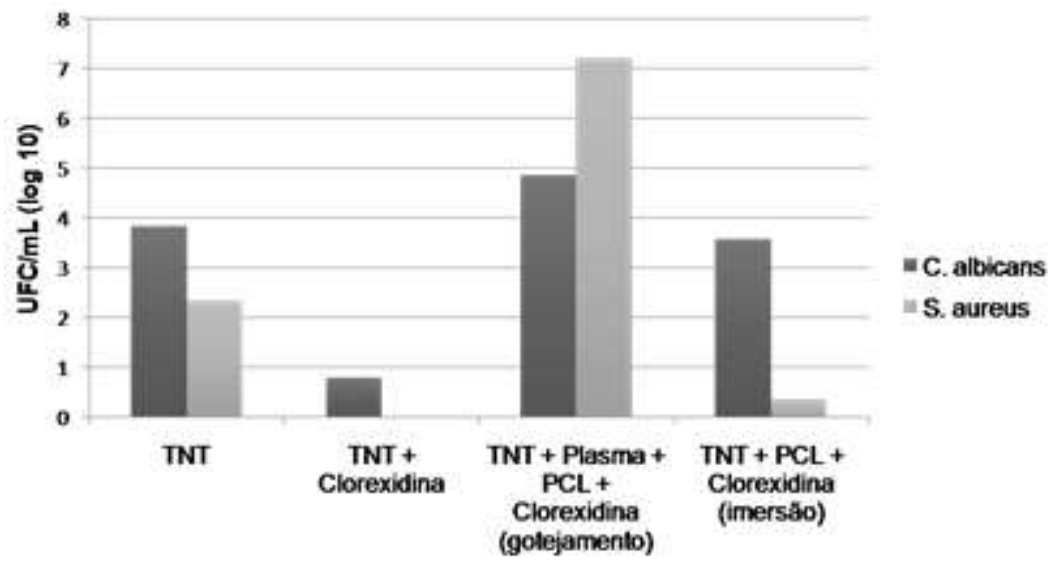

Figura 2: Número de unidades formadoras de colônias por $\mathrm{mL}$ (UFC/mL) para as diferentes condições analisadas.

A Figura 2 apresenta os valores médios de unidades formadoras de colônias para cada superfície analisada, onde é possível observar uma redução após a incorporação de clorexidina, com exceção a incorporação por gotejamento, o que evidencia uma incorporação não suficiente e/ou não homogênea do medicamento. Neste caso, há também uma disparidade com as outras superfícies analisadas e com a literatura, que diz haver uma resistência maior da C. albicans em relação a $S$. aureus quando em meio com presença de clorexidina $^{21,22}$.
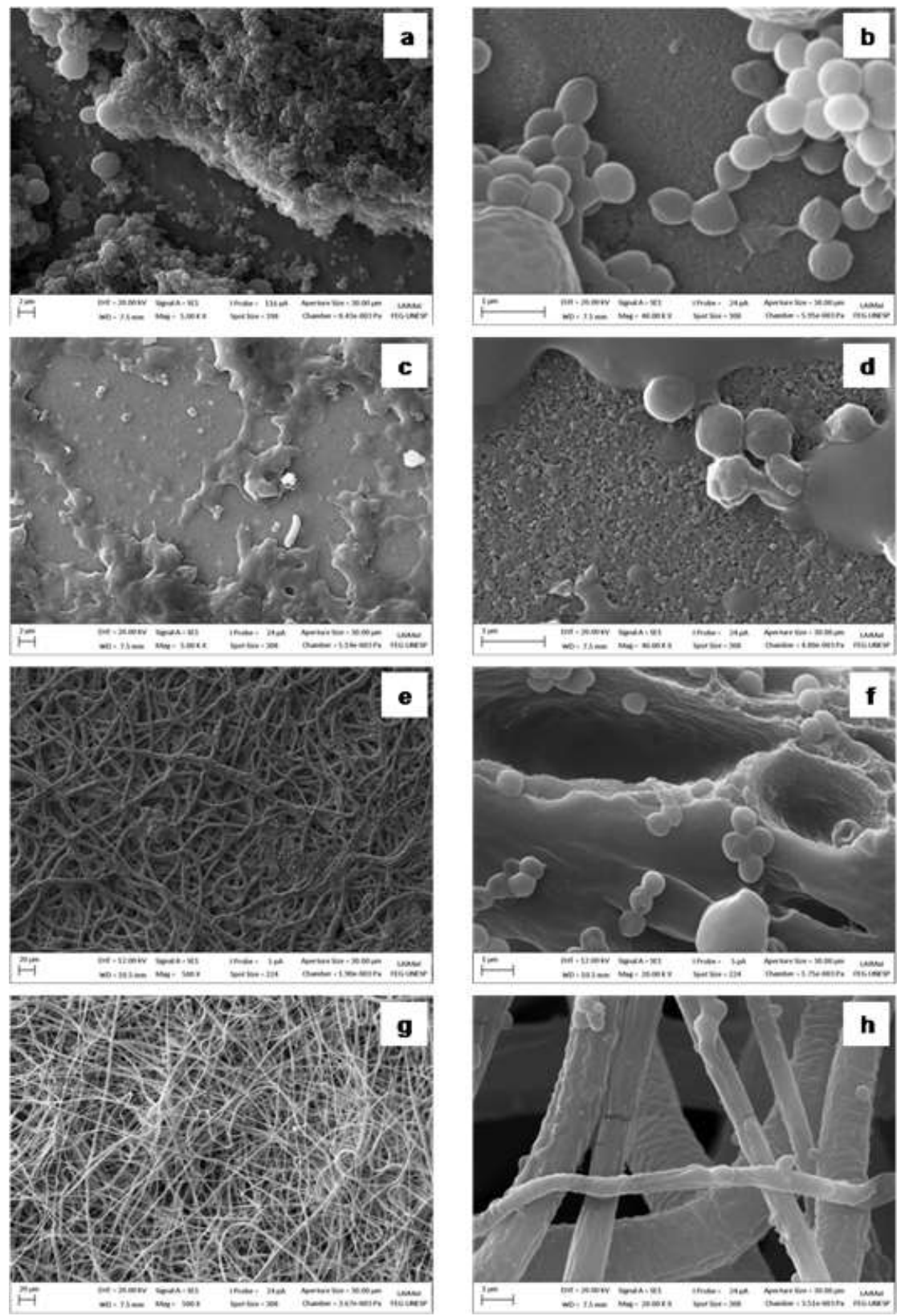

Figura 3: Microscopias eletrônicas dos grupos analisados, após a cultura de bactérias: $(\mathrm{a}, \mathrm{b})$ nanotubos de $\mathrm{TiO}_{2},(\mathrm{c}, \mathrm{d})$ nanotubos de $\mathrm{TiO}_{2}$ + Clorexidina, (f, g) nanotubos de $\mathrm{TiO}_{2}+$ Plasma + PCL + Clorexidina (gotejamento), (h, i) nanotubos de $\mathrm{TiO}_{2}+\mathrm{PCL}+$ Clorexidina (imersão).
O melhor resultado foi encontrado para a amostra sem PCL, porém o polímero pode atuar como regulador da liberação do medicamento, liberando o fármaco lentamente e atuando por mais tempo, o que explicaria valores médios maiores para essa condição quando comparados ao grupo TNT + Clorexidina

A Figura 3 apresenta a superfície das amostras analisadas após a cultura de bactérias. Onde é possível observar a redução dos microorganismos nos grupos TNT + Clorexidina (Figuras 3c e 3d) e TNT + PCL + Clorexidina (imersão) (Figuras $3 \mathrm{~g}$ e 3h).

\section{CONCLUSÃO}

$\mathrm{O}$ crescimento de nanotubos de $\mathrm{TiO}_{2}$ e eletrofiação de poli-caprolactona foram realizados de forma homogênea sobre a superfície da liga Ti7,5Mo.

A incorporação do medicamento por imersão resultou em um efeito bactericida melhor. Estudos sobre o tempo de liberação devem ser realizados para se ter um melhor entendimento de qual tratamento é mais eficiente. Neste estudo a condição TNT + Clorexidina se apresentou mais eficiente.

\section{AGRADECIMENTOS}

Os autores agradecem ao Laboratório de Imagens de Materiais - LAIMat, Univ Estadual Paulista, UNESP Guaratinguetá-SP, Brasil.

\section{REFERÊNCIAS}

1. Alves Rezende MC, Alves AP, Codaro EM, Dutra CAM. Effect of commercial mouthwashes on the corrosion resistance of Ti-10Mo experimental alloy. J Mater Sci Mater Med. 2007; 18(1):149-54.

2. Chelariu R, Bolat G, Izquierdo J, Mareci D, Gordin D M, Gloriant T, Souto RM. Metastable beta Ti-Nb-Mo alloys with improved corrosion resistance in saline solution. Electrochim Acta. 2014; 137:280-9.

3. Kubota S, Johkura K, Asanuma K, Okouchi Y, Ogiwara N, Sasaki K, Kasuga T. Titanium oxide nanotubes for bone regeneration. J Mater Sci: Mater Med. 2004; 15(9): 1031-5.

4. Cai Q, Paulose M, Varghese OK, Grimes CA. The effect of electrolyte composition on the fabrication of selforganized titanium oxide nanotube arrays by anodic oxidation. J Mater Res. 2005;20(1):230-6.

5. Macák JM, Tsuchiya H, Schmuki P. High-aspect-ratio $\mathrm{TiO} 2$ nanotubes by anodization of titanium. Angew Chem Int Engl. 2005;44(14): 2100-2.

6. Macak JM, Tsuchiya H, Taveira L, Ghicov A, Schmuki P. Self-organized nanotubular oxide layers on Ti-6Al$7 \mathrm{Nb}$ and $\mathrm{Ti}-6 \mathrm{Al}-4 \mathrm{~V}$ formed by anodization in $\mathrm{NH} 4 \mathrm{~F}$ solutions. J Biomed Mater Res A. 2005; 75(4):928-33.

7. Song YY, Schmidt-Stein F, Bauer S, Schmuki P. Amphiphilic $\mathrm{TiO} 2$ nanotube arrays: an actively controllable drug delivery system. J Am Chem Soc. 2009; 131(12): 4230-2.

8. Eaninwene G 2nd, Yao C, Webster TJ. Enhanced osteoblast adhesion to drug-coated anodized nanotubular titanium surfaces. Int J Nanomedicine. 2008; 3(2):257-64.

9. Bayram C, Demirbilek M, Yalcın E, Bozkurt M, Doğan $\mathrm{M}$, Denkbaş EB. Osteoblast response on co-modified titanium surfaces via anodization and electrospinning. Appl Surf Sci. 2014; 288: 143-8.

10. Kim SH, Nam YS, Lee TS, Park WH. Silk fibroin nanofiber. Electrospinning, properties, and structure. Polymer J. 2003; 35(2):185-90. 
11. Maheshwari S, Chang HC. Assembly of Multi-Stranded Nanofiber Threads through AC Electrospinning. Adv Mater. 2009; 21(3): 349-354.

12. Bhardwaj N, Kundu SC. Electrospinning: a fascinating fiber fabrication technique. Biotechnol Adv. 2010; 28(3): 325-47.

13. Leung V, Ko F. Biomedical applications of nanofibers. Polym Adv Technol. 2011; 22(3): 350-5.

14. Kolambkar YM, Peister A, Ekaputra AK, Hutmacher DW, Guldberg RE. Colonization and osteogenic differentiation of different stem cell sources on electrospun nanofiber meshes. Tissue Eng Part A. 2010; 16(10): 3219-30.

15. Son YJ, Kim WJ, Yoo HS. Therapeutic applications of electrospun nanofibers for drug delivery systems. Arch Pharm Res. 2014; 37(1):69-78.

16. Escada ALA, Nakazato R, Claro APR. Growth of TiO2 Nanotubes by Anodization of $\mathrm{Ti}-7.5 \mathrm{Mo}$ in $\mathrm{NH}_{4} \mathrm{~F}$ Solutions. Nanosci Nanotech Let. 2013; 5(4):510-2.

17. Wada CM, Rangel ALR, de Souza MA, Almeida RDS, D’Ávila MA, Alves Claro APR, Alves Rezende MCR. Surface Modification of Ti-30Ta Alloy by Electrospun PCL Deposition. Mater Sci Forum. 2016; 869: 930-4.

18. Pereira CA, Romeiro RL, Costa ACBP, Machado AKS, Junqueira JC, Jorge AOC. Susceptibility of Candida albicans, Staphylococcus aureus, and Streptococcus mutans biofilms to photodynamic inactivation: an in vitro study. Laser Med Sci. 2011; 26(3):341-8.

19. Regonini D, Bowen CR, Jaroenworaluck A, Stevens R. A review of growth mechanism, structure and crystallinity of anodized TiO 2 nanotubes. Mater Sci Eng: R: Reports. 2013; 74(12): 377-406.

20. Campoccia D, Montanaro L, Arciola CR. The significance of infection related to orthopedic devices and issues of antibiotic resistance. Biomaterials. 2006; 27(11):2331-9.

21. Tote K, Horemans T, Berghe DV, Maes L and Cos P. Inhibitory effect of biocides on the viable masses and matrices of Staphylococcus aureus and Pseudomonas aeruginosa biofilms. Appl Environ Microbiol. 2010; 76(10): 3135-42.

22. Lamfon H, Porter SR, McCullough M, Pratten J. Susceptibility of Candida albicans biofilms grown in a constant depth film fermentor to chlorhexidine, fluconazole and miconazole: a longitudinal study. J Antimicrob Chemother. 2004; 53(2):383-5.

\section{CONFLITO DE INTERESSES}

Os autores declaram não haver conflitos de interesse.

\section{AUTOR PARA CORRESPONDÊNCIA}

João Pedro Aquiles Carobolante

pedrocarabolante@gmail.com

Submetido em 16/11/2016 Aceito em 05/12/2016 